\title{
Peran Metode Failure Mode and Effect Analysis (FMEA) terhadap Mutu Pelayanan Rumah Sakit: Systematik Review
}

\author{
Anisa Sri Utami ${ }^{1 *}$, Rahmi Fahmy ${ }^{2}$, Zifriyanthi Minanda Putri ${ }^{3}$ \\ ${ }^{1}$ Pasca Sarjana, Fakultas Keperawatan Universitas Andalas, Padang \\ ${ }^{2}$ Fakultas Ekonomi, Universitas Andalas, Padang \\ ${ }^{3}$ Fakultas Keperawatan, Universitas Andalas, Padang \\ *Correspondence email: anisautami95@gmail.com
}

\begin{abstract}
Abstrak. Kejadian medication error, infeksi nosokomial, pasien jatuh, luka tekan (dekubitus) banyak ditemukan di rumah sakit. Kejadian tersebut dapat dicegah dengan mengidentifikasi risiko dan mencari akar masalahnya menggunakan Failure mode and effect analysis (FMEA). Penelitian ini bertujuan mengambarkan efektivitas metode FMEA terhadap mutu pelayanan rumah sakit dengan metode systematic review. Penelitian ini dimulai dari pencarian data menggunakan lima database dengan kata kunci "FMEA or Management Risk or HFMEA" and "service quality" and "hospital" kemudian melakukan skrinning dan penilaian kelayakan terdapat sebanyak 17 artikel. Hasil dari penelitian ini tujuh belas artikel menggambarkan metode FMEA di beberapa proses pelayanan di rumah sakit yang hasil evaluasi metode FMEA dapat meningkatkan mutu pelayanan. Oleh karena itu metode FMEA efektif diterapkan pada proses pelayanan dimulai dari mengidentifikasi resiko kegagalan dalam pelayanan, mengimplementasikan tindakan preventif sehingga meningkatkan mutu pelayanan rumah sakit dalam bentuk dimensi keamanan, efektif dan efisien. Sehingga penelitian ini merekomendasikan penggunaan metode FMEA dalam mengidentifikasi risiko kegagalan untuk meningkatkan kualitas pelayanan.
\end{abstract}

Kata kunci: Failure mode and effect analysis (FMEA); Mutu Pelayanan; Systematic review

Abstract. Incidence of medication errors, nosocomial infections, falling patients, pressure sores (pressure sores) is often found in hospitals. This incident can be prevented by identifying the risk and finding the root of the problem using Failure mode and effect analysis (FMEA). This study aims to describe the effectiveness of the FMEA method on the quality of hospital services using a systematic review method. This research starts from searching for data using five databases with the keywords "FMEA or Risk Management or HFMEA" and "service quality" and "hospital" then doing screenings and feasibility assessments of 17 articles. The results of this study were seventeen articles describing the FMEA method in several hospital service processes where the evaluation results of the FMEA method could improve service quality. Therefore the FMEA method is effectively applied to the service process starting from identifying the risk of failure in service, implementing preventive measures to improve the quality of hospital services in the form of security dimensions, effectiveness, and efficiency. So this study recommends the use of the FMEA method in identifying the risk of failure to improve service quality.

Keywords: Failure Mode and Effect Analysis (FMEA); Service Quality; Systematic review

\section{PENDAHULUAN}

Rumah sakit adalah institusi pelayanan kesehatan yang berperan untuk meningkatkan kesehatan melalui pelayanan yang bermutu sesuai standar yang telah ditetapkan oleh semua petugas kesehatan (UU no 44 tahun 2009). Mutu pelayanan merupakan pelayanan yang diberikan oleh suatu profesi sesuai dengan standar yang dilaksanakan secara menyeluruh sesuai dengan kebutuhan pasien (Nursalam, 2015). Mutu pelayanan seperti indikator hasil pelayanan seperti angka kejadian flebitis, angka kejadian dekubitus, angka kejadian pasien jatuh, angka kesalahan pemberian obat (medication error), tingkat kepuasan pasien dan angka kesalahan pengambilan darah (Nursalam, 2015).

Menurut penelitian yang dilakukan oleh (Lorenzini, Elisiane Cristina \& Annita, 2014) di rumah sakit Brazil utara ditemukan laporan insiden ketidakselamatan pasien pada tahun 2008 - 2012 lebih tinggi di unit rawat inap sebesar $64.8 \%$ dengan pravelensi paling tinggi adalah risiko jatuh $45.4 \%$, medication error $16.7 \%$ dan $16.2 \%$ insiden lainnya. Berdasarkan hasil penelitian terbaru mengatakan bahwa 421 juta pasien rawat inap di dunia setiap tahun nya mendapatkan perawatan yang tidak aman dan sekitar 42.7 juta peristiwa buruk yang terjadi terdiri dari tujuh kejadian yaitu medication error, infeksi saluran kemih terkait kateter, infeksi aliran darah terkait kateter, infeksi nosokomial pneumonia, vena thrombo embolisms, pasien jatuh, luka tekan (dekubitus) (Jha A et al., 2013).

Sejak 1 juli 2001 Joint Commission on Accreditation of Healthcare Organization (JCAHO) mengharuskan setiap rumah sakit yang akan akreditasi sebagai penilaian mutu untuk melaksanakan paling sedikit satu tindakan proaktif dalam mengkaji risiko setiap tahunnya. Failure Mode and Effect Analysis (FMEA) merupakan salah satu metode yang disaran JCAHO untuk digunakan. FMEA adalah suatu metode yang digunakan untuk mengenali proses yang berisiko tinggi, penyebab kesalahan dan cara untuk menyelesaikan permasalahan tersebut secara sistematis 
Anisa Sri Utami et al, Peran Metode Failure Mode and Effect Analysis (FMEA) terhadap Mutu Pelayanan Rumah Sakit: Systematik Review

(Indiati dkk, 2012). Penelitian yang menggambarkan penggunaan FMEA di pelayanan kesehatan dilakukan oleh Lu et al. (2013) menyatakan bahwa FMEA untuk menilai mode kegagalan dan mengidentifikasi tindakan pencegahan untuk mengurangi yang kritis dalam transfusi darah di rumah sakit Cina. Sedangkan Najafpour et al. (2017) melakukan evaluasi risiko proses transfusi darah dalam pengajaran rumah sakit umum dengan menggunakan metode FMEA. Penelitian lainnya yaitu Ofek et al. (2016) menganalisis risiko terkait dengan pengenalan perubahan kebijakan rumah sakit terkait penggunaan solusi kalium klorida intravena untuk mengurangi bahaya pasien. Aranaz-Andres et al. (2017) melakukan FMEA untuk administrasi oral obat cair oleh jarum suntik oral.

Beberapa penelitian tersebut memberikan gambaran bahwa perkembangan metode FMEA dalam mengidentifikasi resiko dipelayanan kesehatan tidak pernah berhenti. Tujuan dari penelitian ini adalah untuk mengetahui efektivitas metode FMEA dalam meningkatkan mutu pelayanan di Rumah Sakit berdasarkan systematic review.

\section{METODE}

Pencarian melalui lima data base yaitu Medline, Science Direct, DOAJ, SAGE dan ProQuest terhadap review studi pada tahun 2015-2020. Pencarian literatur dilakukan bulan Mei - Juli 2020. Studi menggunakan kata kunci ("FMEA" or "Managemet Risk" or "HFMEA") and ("service quality") and ("hospital").

Kriteria inklusi pada penelitian ini studi yang berfokus pada proses pelayanan kesehatan dirumah sakit, Studi yang berfokus pada proses pelayanan kesehatan dirumah sakit, Studi yang menjelaskan efektifnya penggunaan metode FMEA dalam menggali risiko kegagalan sehingga dapat memenuhi dimensi mutu pelayanan (safe, effective, efficient, equitable, timely, person centered, integration) di rumah sakit, sedangkan untuk kriteria ekslusi sebagai berikut Studi yang berfokus pada proses pembuatan suatu obat/alat di rumah sakit, Studi yang menggunakan metode FMEA dan menggabungkan dengan metode lain. Langkah pertama melakukan skrinning berdasarkan judul, abstrak dan keyword didapatkan sebanyak 70 artikel. Artikel tersebut diskrinning kembali dengan melihat keseluruhan teks didapatkan sebanyak 24 artikel. Kemudian dilakukan assesment kelayakan sesuai dengan kriteria inklusi dan the JBI criticcal appraisal didapatkan sebanyak 17 artikel.

\section{HASIL DAN PEMBAHASAN}

Hasil studi dari 17 artikel menyatakan bahwa metode FMEA efektif diterapkan pada proses pelayanan sehingga meningkatkan mutu pelayanan rumah sakit dalam bentuk dimensi keamaman, efektif yang bearti pelayanan tersebut dapat memenuhi kebutuhan pasien dan efisien yaitu memaksimalkan sumber daya dan menghindari pemborosan.

Artikel pertama merupakan penelitian yang dilakukan oleh Flegar-Meštrić et al. (2017) tentang menganalisis resiko proses pra analitik menggunakan metode FMEA di laboraturium yang merupakan indikator data mutu. FMEA mampu mengurangi resiko kegagalan hampir 50\% untuk peningkatan mutu. Artikel kedua menggunakan metode FMEA pada proses pelayanan di ruangan intensive yaitu intervensi Extracorporeal Membrane Oxygenation Activation (ECMO) di ruangan CV-ICU. penelitian ini menyimpulkan FMEA sebagai metode yang digunakan untuk mengidentifikasi kelemahan dan kegagalan dari suatu proses yang komplek, dan meningkatkan kualitas proses pelayanan ECMO di rumah sakit (Nasim et al., 2018).

Artikel ketiga yang dilakukan oleh Arenas Jiménez et al., (2017) menyatakan bahwa penggunaan metode FMEA pada proses pelayanan di ruangan hemodialisis menganalisis sebanyak 21 kesalahan (1 setiap 62 perawatan HD), terutama terkait untuk teknik HD dan administrasi obat yang diresepkan. Sehingga adanya FMEA bertujuan untuk mengidentifikasi risiko potensial dan meningkatkan keamanan perawatan. Artikel ke empat penggunaan metode FMEA pada proses pelayanan manajemen pengobatan di Rawat inap rumah sakit. Sehingga disimpulkan FMEA merupakan alat penilaian resiko yang efektif digunakan sehingga mengurangi kejadian medication error dan proses manajemen obat yang aman untuk pasien (Jain, 2017).

Artiekl kelima penggunaan FMEA juga diterapkan pada proses pelayanan di unit gawat darurat, artikel pertama tentang proses handover di dapartemen IGD rumah sakit. Penelitian ini menyatakan bahwa FMEA dapat mengidentifkasi dan mengevaluasi resiko kegagalan proses handover dan menyediakan kerangka kerja untuk peningkatan kualitas proses handoff (Sorrentino, 2016). Artikel ke enam tentang proses pelayanan Pediatrik unit perawatan intensif (PICU). FMEA dapat membantu peningkatan kesadaran dalam pelaporan kesalahan pada pelayanan pediatrik unit perawatan intensif. Penerapan sistem ini akan meningkatkan kualitas layanan kesehatan (Daverio et al., 2015).

Artikel ketujuh dilakukan oleh Jiang et al., (2015) tentang proses pelayanan di laboratory University Hospital. Hasil penelitian ini menyatakan bahwa FMEA dapat menurun kan resiko error pada klinik laboraturium sehingga meningkatkan kualitas. Artikel ke delapan tentang penelitian di Ruang operasi dengan menggunakan metode FMEA. Metode FMEA menunjukkan bahwa dengan memperbaiki manajemen daftar, atau penjadwalan ulang, mengurangi waktu pasien, memperbaiki alur pelayanan, memperkuat Program Bedah Day Care dan mendirikan klinik Pra- 
Anisa Sri Utami et al, Peran Metode Failure Mode and Effect Analysis (FMEA) terhadap Mutu Pelayanan Rumah Sakit: Systematik Review

anestesi, meningkatkan keseluruhan atau efisiensi pelayanan operasi di rumah sakit (Gaur, 2019).

Artikel kesembilan tentang proses pelayanan pencegahan venous thromboembolic disease (VTD) pada pasien kritis di Ruang ICU dengan metide FMEA. Sehingga metode FMEA dapat mengoptimalkan langkah-langkah profilaksis dalam VTD, dan mencapai standar kualitas (Viejo Moreno et al, 2016). Artikel kesepuluh dilakukan oleh Zervakis Brent (2016) tentang pelaksanaan metode FMEA di pelayanan di ruang operasi. Melakukan FMEA untuk mencegah kesalahan adalah penting dan dapat dilakukan dengan mudah diaplikasi dalam pengaturan rumah sakit untuk mencegah kesalahandan mempromosikan keselamatan pasien.

Artikel kesebelas melakukan identifikasi resiko pada proses pelayanan di unit gawat darurat dengan pendekatan FMEA. Sehingga disimpulkan HFMEA untuk mengidentifikasi kemungkinan kesalahan proses perawatan, penyebab setiap kegagalan mode, dan strategi peningkatan pelayanan yang sangat efektif (Yasamin Molavi et al. 2016). Artikel kedua belas yang dilakukan oleh Moraes et al., (2018) menggunakan metode FMEA terhadap pelayanan orthotics, prosthetics and special materials (OPSM) di rumah sakit. Hasil penelitian mengatakan bahwa metide FMEA membantu menurunkan resiko kegagalan dari proses dan meningkatkan level keamanan dan kualitas pelayanan.

Artikel ketiga belas tentang penggunaan metode FMEA pada pelayanan transfusi darah di rumah sakit. Metode FMEA dapat digunakan untuk meningkatkan keamanan, keandalan, evaluasi risiko, kendali mutu dan proses transfusi darah (Zhila et al, 2017). Artikel keempat belas yang dilakukan oleh Ofek et al., (2016) tentang penggunaan metode FMEA pada proses pelayanan dalam pemberian KCL di rumah sakit. Penggunaan FMEA mampu untuk meningkatkan proaktif keamanan dan proses yang efesien di sistem pelayanan kesehatan.

Artikel kelima belas tentang metode FMEA pada proses pelayanan radiosurgery Gamma Knife di rumah sakit. Implementasi pendekatan FMEA untuk operasi radio Gamma Knife memungkinkan pemahaman yang lebih dalam tentang proses keseluruhan di antara semua profesional terlibat dalam perawatan pasien dan membantu mengidentifikasi kelemahan potensial dalam proses keseluruhan Andy (Yuanguang et al. 2017). Artikel keenam belas dilakukan oleh Maria Ángeles et al. (2017) penggunaan metode FMEA pada proses pelayanan farmasi di dapartemen farmasi rumah sakit. Penilitian ini meningkatkan kesadaran masyarakat pentingnya keselamatan pasien di antara personel yang terlibat dalam proses perawatan farmasi. Artikel ketujuh belas tentang metode FMEA yang diterapkan pada diversion di sistem kesehatan rumah sakit. FMEA pada penelitian ini merupakan sistematik identifikasi untuk mengontrol keuntungan substansi diversi, prioritas dengan mudah dilakukan dan mengembangkan target strategi untuk menurunkan resiko diversi (Nolan, Karen, dkk, 2019).

Penelitian penggunaan FMEA pada pelayanan laboraturium menyatakan bahwa proses praanalitik dengan menggali resiko dan membuat proses baru dengan menggunakan FMEA mampu mengurangi risiko kegagalan hampir 50\% (Flegar-Meštrić et al. 2017). Hal ini sesuai dengan teori yang menyatakan bahwa pendidikan dan pelatihan staff secara berkelanjutan dapat memperkuat dan menambah kinerja yang telah berhasil atau memperbaiki kinerja yang bermasalah (Simamora, 2018). Jiang et al., (2015) menyatakan bahwa FMEA dapat menurun kan risiko error pada klinik laboraturium sehingga meningkatkan kualitas. Hal ini sejalan dengan teori yang mengatakan bahwa Failure Mode And Effect Analysis (FMEA) merupakan suatu metode identifikasi tindakan korektif yang diperlukan untuk mencegah kegagalan dan error dari kejadian dan pencapaian pasien, sehingga menjamin kualitas tertinggi keandalan yang mungkin dalam layanan kesehatan (Chen Liu, 2019).

Penelitian lainnya menggunakan metode FMEA pada proses pelayanan di ruangan intensive yang menyimpulkan FMEA sebagai metode yang digunakan untuk mengidentifikasi kelemahan dan kegagalan dari suatu proses yang komplek, dan meningkatkan kualitas proses pelayanan ECMO di rumah sakit (Nasim et al., 2018). Viejo Moreno et al, (2016) menggunakan metode FMEA pada pelayanan pencegahan venous thromboembolic disease (VTD) pada pasien kritis di Ruang ICU, dan metode tersebut dapat mengoptimalkan langkah-langkah profilaksis dalam VTD, dan mencapai standar kualitas . FMEA dapat membantu peningkatan kesadaran dalam pelaporan kesalahan pada pelayanan pediatrik unit perawatan intensif. Penerapan sistem ini akan meningkatkan kualitas layanan kesehatan (Daverio et al., 2015). Penelitian ini sesuai dengan teori yang menyatakan bahwa FMEA sebagai tindakan korektif yang diperlukan untuk mencegah kegagalan dan kesalahan dari yang terjadi pada pasien, sehingga menjamin kualitas tertinggi dan keandalan yang mungkin dalam layanan kesehatan (Liu, 2019). Sehingga FMEA dapat diterapkan disetiap pelayanan sebagai pemecahan masalah untuk mencapai mutu pelayanan.

Penelitian tentang penggunaan metode FMEA pada pelayanan farmasi FMEA merupakan alat penilaian risiko yang efektif digunakan sehingga mengurangi sebesar 50-60\% kejadian medication error dan proses manajemen obat yang aman untuk pasien (Jain, 2017). Ofek et al., (2016) tentang penggunaan metode FMEA pada proses pelayanan dalam pemberian KCL di rumah sakit, FMEA mampu untuk meningkatkan proaktif keamanan dan proses yang efesien di sistem pelayanan kesehatan. Maria Ángeles et al. (2017) penggunaan metode FMEA untuk meningkatkan kesadaran masyarakat pentingnya keselamatan pasien di antara 
Anisa Sri Utami et al, Peran Metode Failure Mode and Effect Analysis (FMEA) terhadap Mutu Pelayanan Rumah Sakit: Systematik Review

personel yang terlibat dalam proses perawatan farmasi. FMEA merupakan sistematik identifikasi untuk mengontrol keuntungan substansi diversi, prioritas dengan mudah dilakukan dan mengembangkan target strategi untuk menurunkan risiko diversi (Nolan, Karen, dkk, 2019). Hal ini sejalan dengan beberapa penelitian diatas yang menyatakan bahwa FMEA dapat mencegah risiko kegagalan suatu pelayanan yang dapat meningkatkan kualitas pelayanan

Penelitian penggunaan FMEA di unit gawat darurat. Penelitian ini menyatakan bahwa FMEA dapat mengidentifkasi dan mengevaluasi risiko kegagalan proses handover dan menyediakan kerangka kerja untuk peningkatan kualitas proses handoff (Sorrentino, 2016). HFMEA di unit gawat daurat dapat mengidentifikasi kemungkinan kesalahan proses perawatan, penyebab setiap kegagalan mode, dan strategi peningkatan pelayanan yang sangat efektif (Yasamin Molavi et al. 2016).

Penelitian pelayanan di Ruang operasi dengan menggunakan metode FMEA. Metode FMEA menunjukkan bahwa dengan memperbaiki manajemen daftar, atau penjadwalan ulang, mengurangi waktu pasien, memperbaiki alur pelayanan, memperkuat Program Bedah Day Care dan mendirikan klinik Praanestesi, meningkatkan keseluruhan atau efisiensi pelayanan operasi di rumah sakit (Gaur, 2019). Zervakis Brent (2016) menyatakan bahwa bahwa kesalahan pelabelan spesimen merupakan masalah utama keselamatan pasien di RSUP dan pencegahan kesalahan lebih baik dari pada deteksi kesalahan. Melakukan FMEA untuk mencegah kesalahan adalah penting dan dapat dilakukan dengan mudah diaplikasi dalam pengaturan rumah sakit untuk mencegah kesalahandan mempromosikan keselamatan pasien. Moraes et al., (2018) metode FMEA membantu menurunkan risiko kegagalan dari proses dan meningkatkan level keamanan dan kualitas pelayanan. Penelitian menggunakan pendekatan FMEA untuk radiosurgery Gamma Knife memungkinkan pemahaman yang lebih dalam tentang proses keseluruhan di antara semua profesional terlibat dalam perawatan pasien dan membantu mengidentifikasi kelemahan potensial dalam proses keseluruhan (Yuanguang et al. 2017). Penelitian yang dilakukan di ruangan operasi rumah sakit menggambarkan FMEA meningkatkan mutu pelayanan yang digambar dimensi mutu secara teorisafe, effective, efficient, equitable, timely, person centered, integration (Imani, 2017).

Metode FMEA dapat digunakan untuk meningkatkan keamanan, keandalan, evaluasi risiko, kendali mutu dan proses transfusi darah (Zhila et al, 2017). Arenas Jiménez et al., (2017) menyatakan bahwa penggunaan metode FMEA pada proses pelayanan di ruangan hemodialisis FMEA bertujuan untuk mengidentifikasi risiko potensial dan meningkatkan keamanan perawatan.

\section{SIMPULAN}

Penelitian systematik review ini menyatakan bahwa penggunaan metode failure mode and effect analysis (FMEA) efektif digunakan pada proses pelayanan rumah sakit yang hasil akhirnya memenuhi dimensi mutu pelayanan rumah sakit yaitu safe, effective, efficient, equitable, timely, person centered, integration.

\section{DAFTAR PUSTAKA}

Abrahamsen HB, Abrahamsen EB, Hoyland S. (2016). On the need for revising healthcare failure mode and effect analysis for assessing potential for patient harm in healthcare processes. Reliab Eng Syst Saf 155:160-168

Arenas Jiménez, M. D., Ferre, G., \& Álvarez-Ude, F. (2017). Strategies to increase patient safety in Hemodialysis: Application of the modal analysis system of errors and effects (FEMA system). Nefrologia, 37(6), 608-621. https://doi.org/10.1016/j.nefroe.2017.11.011

Aranaz-Andres JM, Bermejo-Vicedo T, Munoz-Ojeda I, Delgado-Silveira E, Chamorro-Rubio S, Fernandez-Puentes A, Garcia-Collia M, GuerraAlia EM (2017) Failure mode and effects analysis applied to the administration of liquid medication by oral syringes. Farmacia Hosp 41(6):674-677

Bakhri, M. H. (2017). Manajemen Keperawatan, Konsep dan Aplikasi dalam Praktik Keperawatan Profesional. Pustaka Baru Press.

Daverio, M., Fino, G., Luca, B., Zaggia, C., Pettenazzo, A., Parpaiola, A., Lago, P., \& Amigoni, A. (2015). Failure mode and effective analysis ameliorate awareness of medical errors: a 4-year prospective observational study in critically ill children. Paediatric Anaesthesia, 25(12), 1227-1234. https://doi.org/10.1111/pan.12772

Faiella, G., A, P., BD, F., P, C., M, C., NA, S., \& N, S. (2018). Expanding healthcare failure mode and effect analysis: a composite proactive risk analysis approach. Reliab Eng Syst Saf, 169, 117-126.

Flegar-Meštrić, Z., Perkov, S., Radeljak, A., Kardum Paro, M. M., Prkačin, I., \& Devčić-Jeras, A. (2017). Risk analysis of the preanalytical process based on quality indicators data. Clinical Chemistry and Laboratory Medicine, 55(3), 368377. https://doi.org/10.1515/cclm-2016-0235

Gaur, K. (2019). Systematic and quantitative assessment and application of FMEA and Lean six sigma for reducing non productive time in operation theatre of a Tertiary Care Hospital in a metropolis. Perioperative Care and Operating Room Management, 16(December 2018), 100075. https://doi.org/10.1016/j.pcorm.2019.100075

Hassani S, D. (2015). 30-Day Survival Probabilities as a Quality Indicator for Norwegian Hospitals: Data Management and Analysis. PLoS ONE, 10, 9. 
Anisa Sri Utami et al, Peran Metode Failure Mode and Effect Analysis (FMEA) terhadap Mutu Pelayanan Rumah Sakit: Systematik Review

Iman, A. T., \& Dewi, L. (2017). Manajemen Mutu Informasi Kesehatan 1: Quality Assurance. Pusat Pengendalian SDM Kesehatan Badan Penegmbangan dan Pemberdayaan SDM Kesehatan.

Jain, K. (2017). Use of failure mode effect analysis (FMEA) to improve medication management process. The Eletronic Library, 34(1), 1-5. https://doi.org/10.1108/IJHCQA-09-2015-0113

Jha A, L. I., C, A.-L., N, P.-P., H, W., \& D., B. (2013). The global burden of unsafe medical care: an observational study. BMJ Qual Saf, 22(10), 809815.

Jiang, Y., Jiang, H., Ding, S., \& Liu, Q. (2015). Application of failure mode and effects analysis in a clinical chemistry laboratory. Clinica Chimica Acta; International Journal of Clinical Chemistry, 448 , $80-85$. https://doi.org/10.1016/j.cca.2015.06.016

JJ, A. V., \& Gómez Sánchez A, Nieto Guindo M, F. V. (2014). Using failure mode and effects analysis to improve the safety of neonatal parenteral nutrition. Am J Health Syst Pharm, 71, 12101218.

Lu Y, Teng F, Zhou J, Wen A, Bi Y (2013) Failure mode and effect analysis in blood transfusion: a proactive tool to reduce risks. Transfusion 53(12):3080-3087

Liu, H. (2019). Failure mode and effects analysis for proactive healthcare risk evaluation: A systematic literature review. December. https://doi.org/10.1111/jep.13317

Lorenzini, ElisianeCristina, A., \& Annita, J. (2014). Segurança do paciente: análise dos incidentes notifi cados em um hospital do sul do Brasil. Rev Gaúcha Enferm, 35(2), 121-127.

MacDonald E, Fox E, Tyler L (2011) Drug shortages: process for evaluating impact on patient safety. Hosp Pharm 46(12):943-951

Maria Ángeles, C. V., Juan Enrique Martínez, de la P., José Antonio, M.-M., \& Juan José, P. L. (2017). Identification and prioritisation of risks in a hospital pharmacy using healthcare failure mode and effect analysis - ProQuest. Bmj. https://doi.org/10.1136/ ejhpharm-2017-001242.

Marquis, B. L., \& Huston, C. J. (2012). Leadership Role and Management Function in Nursing (7 th). wolters Kluwer Health.

Moraes, C. D. S., Rabin, E. G., \& Viégas, K. (2018). Assessment of the care process with orthotics, prosthetics and special materials. Revista Brasileira de Enfermagem, 71(3), 1099-1105. https://doi.org/10.1590/0034-7167-2017-0031

Najafpour, Z., Mojtaba, H., Faranak, B., \& Efat, M. (2017). Preventing blood transfusion failures: FMEA, an effective assessment method ProQuest. BMC Health Serv Res, 17, 453. https://doi.org/10.1186/s12913-017-2380-3

Nasim, F., Poterucha, J. T., Daniels, L. M., Park, J. G., Seelhammer, T. G., Bohman, J. K., Friedrich, T. P., Blau, C. L., Elmer, J. L., \& Schears, G. J. (2018). Practical Implementation of Failure Mode and Effects Analysis for Extracorporeal Membrane Oxygenation Activation. American Journal of Medical Quality, 33(5), 523-529. https://doi.org/10.1177/1062860618754703

Nolan, K., Zullo, A. R., Bosco, E., Marchese, C., \& Berard-Collins, C. (2019). Controlled substance diversion in health systems: A failure modes and effects analysis for prevention. American Journal of Health-System Pharmacy, 76(15), 1158-1164. https://doi.org/10.1093/ajhp/zxz116

Nursalam. (2015). Manajemen Keperawatan. Salemba Medika : Jakarta.

Ofek, F., Magnezi, R., Kurzweil, Y., Gazit, I., Berkovitch, S., \& Tal, O. (2016). Introducing a change in hospital policy using FMEA methodology as a tool to reduce patient hazards. Israel Journal of Health Policy Research, 5(1). https://doi.org/10.1186/s13584-016-0090-7

Sorrentino, P. (2016). Use of failure mode and effects analysis to improve emergency department handoff processes. Clinical Nurse Specialist, 30(1), 28-37. https://doi.org/10.1097/NUR.0000000000000169

Viejo Moreno, R., Sánchez-Izquierdo Riera, J. Á., Molano Álvarez, E., Barea Mendoza, J. A., Temprano Vázquez, S., Díaz Castellano, L., \& Montejo González, J. C. (2016). Improvement of the safety of a clinical process using failure mode and effects analysis: Prevention of venous thromboembolic disease in critical patients. Medicina Intensiva (English Edition), 40(8), 483490. https://doi.org/10.1016/j.medine.2016.02.004

WHO, R. office for S.-E. A. (2016). Regional strategy for patient safety in the WHO South-East Asia Region (2016-2025).

Xu, A. Y., Jagdish, B., Greg, B., \& John, F. (2017). Failure modes and effects analysis (FMEA) for Gamma Knife radiosurgery - ProQuest. Wiley Online https://doi.org/10.1002/acm2.12205

Yasamin Molavi, T., Fatemeh, R., \& Hojat, S. (2016). Risk assessment of the emergency processes: Healthcare failure mode and effect analysis. World Journal of Emergency Medicine, 7(2), 97104. https://doi.org/10.5847/wjem.j.1920

Zervakis Brent, M. A. (2016). OR Specimen Labeling. AORN Journal, 103(2), 164-176. https://doi.org/10.1016/j.aorn.2015.12.018 